\title{
The dynamical mechanical properties of tungsten under compression at working temperature range of divertors
}

\author{
C.C. Zhu ${ }^{\text {a, b }}$, Y.T. Song ${ }^{\text {b, a }}$, X.B. Peng ${ }^{\text {b, }}{ }^{*}$, Y.P. Wei ${ }^{\text {c }}$, X. Mao ${ }^{\text {b }}$, W.X. Li ${ }^{\text {a }}$, X.Y. Qian ${ }^{\text {a }}$ \\ a School of Nuclear Science and Technology, University of Science and Technology of China, Hefei 230026, PR China \\ ${ }^{\mathrm{b}}$ Institute of Plasma Physics, Chinese Academy of Sciences, Hefei 230031, PR China \\ ${ }^{\mathrm{c}}$ Key Laboratory of Mechanics in Fluid Solid Coupling Systems, Institute of Mechanics, Chinese Academy of Sciences, Beijing 100190, PR China
}

\section{H I G H L I G H T S}

- Test research on dynamic properties of tungsten at working temperature range and strain rate range of divertors.

- Constitutive equation descrbing strain hardening, strain rate hardening and temperature softening.

- A guidance to estimate dynamical response and damage evolution of tungsten divertor components under impact.

\section{A R T I C L E I N F O}

\section{Article history:}

Received 13 April 2015

Received in revised form

16 November 2015

Accepted 24 November 2015

Available online 2 December 2015

\section{Keywords:}

Tungsten

Electromagnetic loads

Dynamic mechanical compressive behavior Constitutive equation

Divertor

\section{G R A P H I C A L A B S T R A C T}

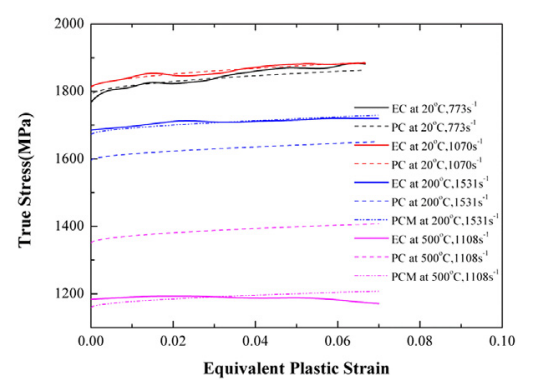

\begin{abstract}
A B S T R A C T
In the divertor structure of ITER and EAST with mono-block module, tungsten plays not only a role of armor material but also a role of structural material, because electromagnetic (EM) impact will be exerted on tungsten components in VDEs or CQ. The EM loads can reach to $100 \mathrm{MN}$, which would cause high strain rates. In addition, directly exposed to high-temperature plasma, the temperature regime of divertor components is complex. Aiming at studying dynamical response of tungsten divertors under EM loads, an experiment on tungsten employed in EAST divertors was performed using a Kolsky bar system. The testing strain rates and temperatures is derived from actual working conditions, which makes the constitutive equation concluded by using John-Cook model and testing data very accurate and practical. The work would give a guidance to estimate the dynamical response, fatigue life and damage evolution of tungsten divertor components under EM impact loads.
\end{abstract}

() 2015 Elsevier B.V. All rights reserved.

\section{Introduction}

As an armor material, tungsten is of many good properties, such as high melting point, low sputtering rate, reasonable thermal conductivity and high strength, which make it widely used in the divertors of many fusion devices all over the world [1-4].

\footnotetext{
* Corresponding author

E-mail address: pengxb@ipp.ac.cn (X.B. Peng).
}

Nowadays, under normal operating conditions heat load on the first wall is around $2 \mathrm{MW} / \mathrm{m}^{2}$, and about $15 \%$ of the total fusion power has to be removed by divertors while peak loads of $10-20 \mathrm{MW} / \mathrm{m}^{2}$ have to be considered [5]. Benefitting from its high heat conduction ability and great thermal load capacity, mono-block structure has been employed in the divertors of many fusion devices to meet the serious heat transmission needs, such as ITER [6] and EAST [7]. In the mono-block structure, tungsten plays not only a role of armor material but also a role of structural material, due to huge 
electromagnetic (EM) loads besides thermal stress exerted on the tungsten structure. According to G. Sannazzaro's research, the EM force is most severe compared to other mechanical loads acting on tokamak structures, e.g. dead weight, seismic load and hydraulic pressure [8]. Besides that, thermal loads including the surface heat fluxes from plasma and the neutron heat generation are an important design driver. Thermal stress induced in thermal expansion is second stress, while EM force would generate primary stress. The effect of thermal stress on dynamic structural analysis was not considered in most articles. So the two different kinds of loads were not comparatively discussed in this paper. On one hand, eddy currents which are induced by the decay of plasma current and the change of plasma shape of disrupting plasma according to the Faraday law, would generate an electromagnetic force on the mono-block structure in the magnetic field. On the other hand, halo currents flow through the structures when vertical displacement events (VDEs) occur and the plasma current makes a contact to surrounding PFC, subsequently the currents would also generate an electromagnetic force on the mono-block structure in the magnetic field. Compared to eddy currents, halo currents is much higher and larger EM loads acted on the tungsten structure in the VDEs. The vertical force and the vertical moment are major load part for the divertor components when VDEs happen. As the property of plasma hasn't been researched very clearly, the process of VDEs cannot be quantified very precisely. Most researchers utilized DINA to simulate the plasma in VDEs in order to calculating electromagnetic loads of the vacuum vessel and the in-vessel components. By using the same method but a new method to simplify modeling process, Sunil Pak et al. have done much effective electromagnetic load calculation work on the ITER machine [9]. In their study on slow downward VDEs, it is indicated that the vertical forces exerted on the $20^{\circ}$ sector of the divertor model get up to $5 \mathrm{MN}$ from $0 \mathrm{MN}$ in a linear way during about $400 \mathrm{~ms}$, and decay to $0 \mathrm{MN}$ in a negative exponent way during the following $700 \mathrm{~ms}$. The duration of vertical force is very short, but the magnitude of vertical force is large, which would make the EM impact loads cause high strain rates on the divertor targets. Hence with the operation parameters constantly improved to reach the next goals of tokamak experiment device, the EM impact exerted on divertor components will be larger.

As the vertical force is major load exerted on the tungsten components, the compressive impact is a great threat to the durability of tungsten divertors. In order to figure out the dynamical mechanical property, an experiment on tungsten employed in the EAST divertor was performed using a Kolsky bar system (also known as a Split Hopkinson pressure bar, SHPB) [10]. As supplementary, a quasi-static compression test with a strain rate of $10^{-3} \mathrm{~s}^{-1}$ at the room temperature was carried out to acquire basic stress-strain relationship using an MTS hydro-servo system. The experiment is introduced in Section 2. The respective effects of the strain rate and temperature on the stress-strain characteristics of the impacted specimens are identified and discussed in Sections 3.1 and 3.2. In Section 3.3, a constitutive equation involving five material constants was built by using John-Cook model to describe the effects of strain hardening, strain rate hardening and temperature softening [11]. The predicted curves at various cases calculated by the constitutive equation were compared with the experimental curves to evaluate the reliability. The two kinds of curves fit very well at room temperature, but there is an obvious difference between the two kinds of curves. As a result, the thermal softening exponent $\mathrm{m}$ was corrected by a negative exponential function and the error was greatly reduced. Some conclusions have been made in Section 4 . The model can be used to estimate the dynamic response of the tungsten divertor under the electromagnetic impact, which is very important to design and optimize the divertor structure in the future fusion power reactors.

\section{Experimental}

Currently, commercial purity tungsten produced at Advanced Technology \& Materials Co., Ltd. (AT\&M) is employed for the EAST divertor application. The EAST project chose powder metallurgical methods utilizing mechanical alloying (MA) for the manufacture of Ultra-fine grained (UFG) W compacts. Microstructural modification by hot plastic working has been applied to the compacts processed by MA in a purified $\mathrm{Ar}$ or $\mathrm{H}_{2}$ atmosphere and hot isostatic pressing (HIP) [12]. The modified compacts exhibit a very high fracture strength and appreciable ductility at room temperature. The commercial purity tungsten meets ASTM B760-86 (1999) Standard Specification for Tungsten Plat, and the chemical composition of pure $\mathrm{W}$ is shown in Table 1.

A quasi-static compression test with a strain rate of $10^{-3} \mathrm{~s}^{-1}$ in the room temperature was carried out by using an MTS hydro-servo system. While pure tungsten is of a very high yield strength, it is quite important to reduce the draw ratio instead of normal values (they are $0.5,1,1.5$ ) for getting high strain rates and forbidding Pressure-Bending effect of the incident bar and transmission bar. Therefore, cylinders of 4,5 or $6 \mathrm{~mm}$ diameter and $8 \mathrm{~mm}$ height were chosen as the dynamic compression test specimens. Considering that $W$ has a very high strength, the stress rate of $W$ at $400 \mathrm{~s}^{-1}$ is approximately estimated to reach a great value of $16000 \mathrm{GPa}$ per second. Referring to the testing work about pure $\mathrm{W}$ of $\mathrm{Z}$. Pan et al. [13], high strain rates ranging from 400 to $1600 \mathrm{~s}^{-1}$ were chosen to assess the effect of strain rate hardening to $\mathrm{W}$. Because the heating temperatures below $800{ }^{\circ} \mathrm{C}$ were accurately provided by the heating furnace in the lab and mechanical properties at high temperature above $700{ }^{\circ} \mathrm{C}$ could be extrapolated by researching the trend of testing curves, Dynamic tests were performed at room temperature, $200,300,500,700{ }^{\circ} \mathrm{C}$ by means of a spilt Hopkinson pressure bar. Schematic diagram of the apparatus is given in Fig. 1. A specimen was cemented with artificial butter between the incident bar and transmitter bar. A heating furnace completely surrounding the specimen was employed to ensure experiment temperatures. The reflected and transmitted pulses are recorded by strain gauges bonded to the middle of two bars. And two cooling systems were respectively installed at the ends of the incident and transmission bars near the specimen, which could protect the strain gages from heat flow transported from the heating furnace because strain gages are very sensitive to heat flow. Based on data recorded through the strain gages on the incident bar and transmitter bar, specimen strain, strain rate and stress can be obtained according to the following formulas which are derived from the onedimensional stress wave theory:

$$
\begin{aligned}
& \dot{\varepsilon}(t)=\frac{2 c}{l_{0}} \varepsilon_{r}(t) \\
& \varepsilon(t)=\frac{2 c}{l_{0}} \int_{0}^{t} \varepsilon_{r}(t) d t
\end{aligned}
$$

$\sigma(t)=\frac{A}{A_{0}} E \varepsilon_{t}(t)$

where $E, c, A$ refer to the elastic modulus, the elastic wave velocity and the cross-sectional area of the pressure bar, respectively. $A_{0}$ and $l_{0}$ are the cross-sectional area and the length of the specimen, respectively. 
Table 1

Chemical composition (in wt. \%) of pure W (based on ASTM B760-86 (1999) Standard Specification for Tungsten Plate).

\begin{tabular}{|c|c|c|c|c|c|c|c|}
\hline Chemical composition & $\mathrm{W}$ & $\mathrm{C}$ & $\mathrm{O}$ & $\mathrm{N}$ & $\mathrm{Fe}$ & $\mathrm{Ni}$ & $\mathrm{Si}$ \\
\hline Max wt.\% & Bal. & 0.01 & 0.01 & 0.01 & 0.01 & 0.01 & 0.01 \\
\hline Allowable range in wt.\% & Bal. & \pm 0.002 & $+10 \%$ relative & +0.0005 & +0.001 & +0.001 & +0.001 \\
\hline
\end{tabular}

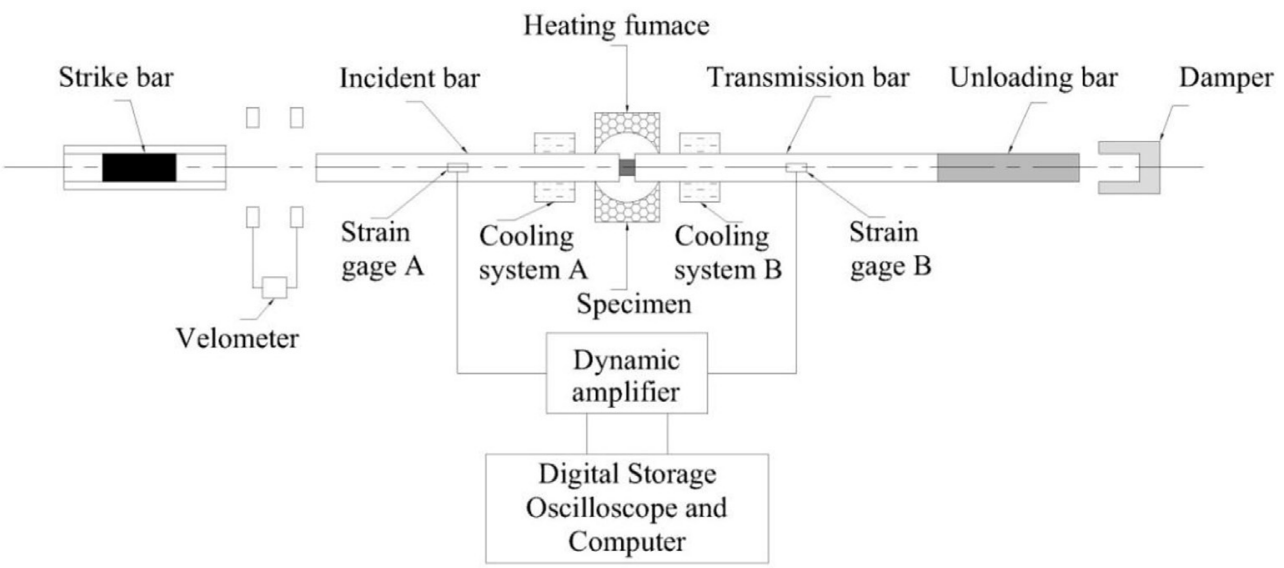

Fig. 1. The schematic of the Split Hopkinson Pressure Bar.

\section{Result and discussion}

\subsection{Strain rate hardening}

The dynamic and quasi-static true stress-true strain curves at room temperature for the tungsten are shown in Fig. 2. Compared to the quasi-static stress-strain curve, the dynamic stress-strain curves of the tungsten specimens show flow softening. At small strains, the dynamic curves exhibit strain hardening. Then the dynamic curves level off, mainly due to adiabatic heating. The strainrate dependence is very important to characterize plastic deformation of metals. In this experiment, the speed of the bullet made of precipitation hardness stainless steel was constantly increased to impose different strain rates. As is shown in Fig. 2, the flow stress trended to go up when the strain rate was increased. But the tendency is not apparent in strain rates above $1000 \mathrm{~s}^{-1}$. With the strain rate increased, the yield stress of the tungsten rises in the same

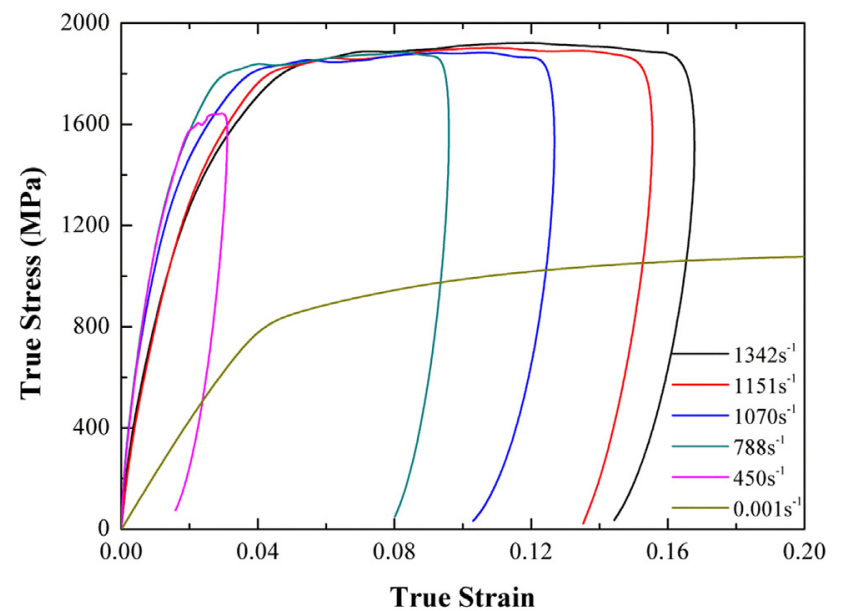

Fig. 2. The true-stress-true-strain curves of $\mathrm{W}$ samples with strain rate varied at room temperature. way. Table 2 shows yield stresses of tungsten samples at different strain rates. The yield stress at the ambient temperature increased from $1580 \mathrm{MPa}$ to $1840 \mathrm{MPa}$ when the testing strain rate was improved from 450 to $1342 s^{-1}$. The strain rate hardening effect for the tungsten armor material is not very strong.

\subsection{Thermal softening}

Another important parameter that characterizes the flow stress of metals is the temperature dependence. Five temperature points ranging from $200{ }^{\circ} \mathrm{C}$ to $700{ }^{\circ} \mathrm{C}$ that approximately cover actual working temperatures of the tungsten divertor were chosen to explain the temperature effect of tungsten under dynamic loads. The dynamic stress-strain curves at different temperatures are shown in Fig. 3. For elastic segment of these curves, curves at 300, 500 and $700{ }^{\circ} \mathrm{C}$ got a similar slope which was bigger than the slope of the curve at $20^{\circ} \mathrm{C}$, and the slope of the $200^{\circ} \mathrm{C}$ curve appeared to be the smallest. The scenario that the metal gets a higher elasticity modulus at a temperature above $300{ }^{\circ} \mathrm{C}$ than at a temperature below $300{ }^{\circ} \mathrm{C}$ is wired because elasticity modulus represents the value of interatomic bonding force and with the temperature going up interatomic bonding force trend to be smaller. Through a few times tests under dynamic compression, a conclusion has been made to explain the contradiction between the elasticity modulus and the temperature rise. When the specimens were heated, their volume would expand freely if there was no constraint on them. Therefore, the axial free length of specimens would be longer, and the slopes of the elastic segment of true-stress-true-strain curves at $200,300,500$ and $700{ }^{\circ} \mathrm{C}$ are bigger than their true elasticity modulus. Elastic segments of these curves at 300,500 and $700{ }^{\circ} \mathrm{C}$ got bigger slopes than that at 20 and $200{ }^{\circ} \mathrm{C}$ because the axial free length of specimens heated from $200{ }^{\circ} \mathrm{C}$ to $300{ }^{\circ} \mathrm{C}$ increased a lot.

Table 2

Yield stresses of tungsten samples at different strain rates.

\begin{tabular}{lllllll}
\hline Strain rate $\left(s^{-1}\right)$ & $10 \mathrm{E}-3$ & 450 & 788 & 1070 & 1151 & 1342 \\
\hline Yield stress $(\mathrm{MPa})$ & 890 & 1580 & 1792 & 1814 & 1802 & 1840 \\
\hline
\end{tabular}




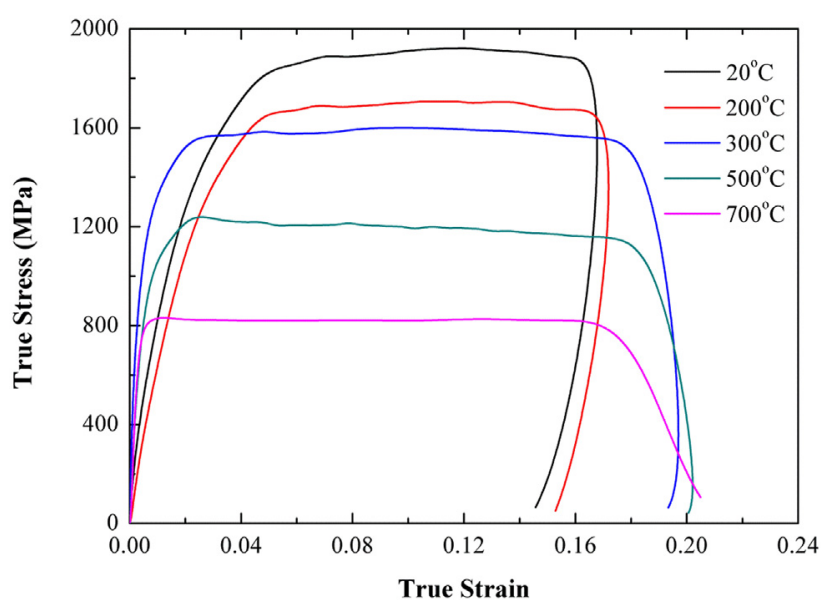

Fig. 3. The dynamic true-stress-true-strain curves of $\mathrm{W}$ samples at different temperatures when the strain rate is about $1300 \mathrm{~s}^{-1}$.

At similar strain rates and the same plastic strain, the flow stress decreased when temperature was increased. With the temperature increased, the yield stress of the tungsten declines in the same way. Table 3 shows yield stresses of the tungsten at different temperatures. The yield stress at the strain rate of about $1300 \mathrm{~s}^{-1}$ decreases from $1840 \mathrm{MPa}$ to $808 \mathrm{MPa}$ when the testing temperature is improved from the ambient temperature to $700{ }^{\circ} \mathrm{C}$. It is quite distinct that the temperature has a great influence on the tungsten armor material.

\subsection{Constitutive equation}

According to Johnson-Cook model, the flow stress is expressed as:

$\sigma_{e}=\left(A+B\left(\varepsilon_{e}^{p}\right)^{n}\right)\left(1+C \ln \dot{\varepsilon}^{*}\right)\left(1-T^{* m}\right)$

where $\sigma_{e}$ refers to the (Von Mises) flow stress, $A$ is the yield stress at reference temperature and reference strain rate, $B$ is the coefficient of strain hardening, $n$ is the strain hardening exponent, $\varepsilon_{e}^{p}$ is the equivalent plastic strain, $\dot{\varepsilon}^{*}=\dot{\varepsilon}^{p} / \dot{\varepsilon}_{0}$ is the dimensionless strain rate with $\dot{\varepsilon}^{p}$ and $\dot{\varepsilon}_{0}$ respectively being the equivalent plastic strain rate, the reference strain rate, and $T^{*}$ is the dimensionless temperature and expressed as:

$T^{*}=\frac{T-T_{r}}{T_{m}-T_{r}}$

where $T$ refers to the current absolute temperature, $T_{m}$ refers to the melting temperature ( $3673 \mathrm{~K}$ for the tungsten employed in EAST), and $T_{r}$ refers to the room temperature. $C$ and $m$ are material constants that represent the coefficient of strain rate hardening and thermal softening exponent, respectively.

The strain rate of $10^{-3} \mathrm{~s}^{-1}$ in the quasi-static compression test was adopted as the reference strain rate to predict the flow behavior of tungsten armor material. At the reference strain rate and room temperature, Eq. (4) will reduce to:

Table 3

Yield stresses of tungsten samples at different temperatures when the strain rate is about $1300 s^{-1}$

\begin{tabular}{llllll}
\hline Temperature $\left({ }^{\circ} \mathrm{C}\right)$ & 20 & 200 & 300 & 500 & 700 \\
\hline Yield stress $(\mathrm{MPa})$ & 1840 & 1655 & 1563 & 1236 & 830 \\
\hline
\end{tabular}

$\sigma_{e}=A+B\left(\varepsilon_{e}^{p}\right)^{n}$

The value of $A$ is calculated from the yield stress (i.e. the stress at $0.2 \%$ strain) of the flow curve in the quasi-static compression test. Substituting the value of $A$ in the left side and right side of Eq. (3), Eq. (3) can be transformed to:

$\ln \left(\sigma_{e}-A\right)=\ln B+n \ln \varepsilon_{e}^{p}$

Using the flow stress data at various strains, $B$ and $n$ are obtained by fitting at least squares principle. At the room temperature, there is no thermal softening effect because $T^{*}$ equals to 0 . So Eq. (4) can be expressed as:

$\sigma_{e}=\left(A+B\left(\varepsilon_{e}^{p}\right)^{n}\right)\left(1+C \ln \dot{\varepsilon}^{*}\right)$

Using the flow stress data for a particular equivalent plastic strain such as 0.025 at various rates, $C$ is calculated from the slope of $\sigma_{e} / A+B\left(\varepsilon_{e}^{p}\right)^{n}$ vs. $\ln \dot{\varepsilon}^{*}$ plot. Similarly, using the flow stress data for a particular equivalent plastic strain and a particular strain rate at various temperatures, $\mathrm{m}$ is obtained from the slope of $\ln \left\{1-\sigma_{e} /\left[A+B\left(\varepsilon_{e}^{p}\right)^{n}\right]\left(1+C \ln \dot{\varepsilon}^{*}\right)\right\}$ vs. $\ln T^{* m}$ plot.

The material constants of the JC model parameters are given in Table 4 . The predicted curves are drawn by using the parameters in Table 4. As shown in Fig. 4, which consistent very well with the experimental stress-strain curves at room temperature, while there is a significant difference between the predicted stress-strain curves and the experimental stress-strain curves with the temperature going up. A method based on analyzing the relation between the thermal softening exponent $m$ and the current absolute temperature $\mathrm{T}$ is used to optimize the ability of the JC model which characterizes the temperature dependence under the dynamic compression. After analyzing the trend of stress-strain curves at various temperatures, the thermal softening exponent $\mathrm{m}$ can be fitted as a function of the current absolute temperature $\mathrm{T}$, seen in Eq. (9). The new predicted stress-strain curves were drawn in Fig. 4. From the comparison between the experimental curves and the predicted curves calculated by adopting the corrected $\mathrm{m}$, it is very clear that the new model is of great capability to explain the deformation behavior of the tungsten material under dynamic compression at high temperatures.

$m=A^{*} \exp \left(-T / T_{1}\right)+m_{0}$

where $A$ equals to $1.79, T_{1}$ equals to $854 K$, and $m_{0}$ equals to -0.203 .

\section{Conclusions}

There is a big difference between dynamic compression and quasi-static compression for tungsten because the strain rate hardening is quite strong. The yield stress at the ambient temperature increases from $1580 \mathrm{MPa}$ to $1840 \mathrm{MPa}$ when the testing strain rate is improved from 450 to $1342 \mathrm{~s}^{-1}$. But the yield stress of $\mathrm{W}$ at a strain rate of $10^{-3} \mathrm{~s}^{-1}$ is just $890 \mathrm{MPa}$. With the temperature rising, the thermal softening effect on the $\mathrm{W}$ material will not keep the same. The yield stress will decrease with the temperature becoming higher and higher. So, it comes to be unadvisable when the researchers calculate the stress and strain status of the diveror

Table 4

Parameters of the Johnson-Cook Model for pure tungsten.

\begin{tabular}{llllll}
\hline Parameter & $A(\mathrm{MPa})$ & $B(\mathrm{MPa})$ & $n$ & $C$ & $m$ \\
\hline Value & 890 & 144 & 0.50258 & 0.0745 & 0.69596 \\
\hline
\end{tabular}




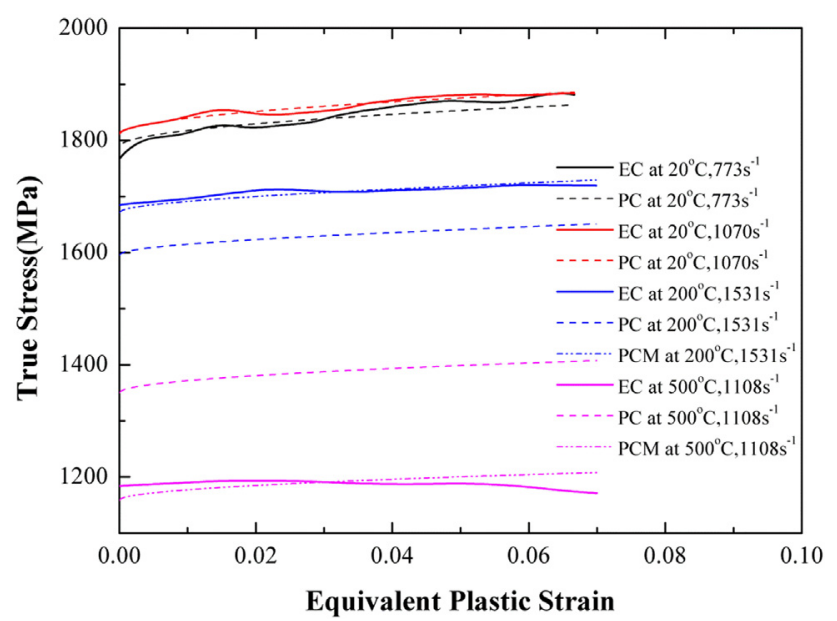

Fig. 4. Comparison of the true flow stress-equivalent plastic strain relationship of $\mathrm{W}$ for the experimental data, the Johnson-Cook constitutive equation and the modified Johnson-Cook constitutive equation with a corrected $m$. EC, PC and PCM refer to experimental curve, predicted curve and predicted curve with a corrected $m$, respectively. Different colors represent different scenarios (For interpretation of the references to colour in this figure legend, the reader is referred to the web version of this article.).

under a EM impact load imposed in VDE or CQ by using a static structural analysis method. It is inferred that the yield stress of tungsten at a temperature of about $400{ }^{\circ} \mathrm{C}$ under a dynamic compression load reaches to a magnitude of about $1200 \mathrm{MPa}$. However, the maximum stress imposed by EM impact in the divertors of fusion power reactors nowadays is only about $200 \mathrm{MPa}$. Discussion about fatigue life and damage evolution of the tungsten divertors under dynamic compression is a critical question to the divertor designers and researchers. And the constitutive equation and discussions will be helpful to the future design and research of tungsten divertor.

\section{Acknowledgments}

We would like to acknowledge the support and contributions of Professor Y. f. Fan at The State Key Laboratory of Nonlinear Mechanics, Institute of Mechanics, Chinese Academy of Sciences. This work was supported by National Magnetic Confinement Fusion Science Program of China under Contract No. 2014GB101001.

\section{Appendix}

$\dot{\varepsilon}(t)=\frac{2 c}{l_{0}} \varepsilon_{r}(t)$

$\varepsilon(t)=\frac{2 c}{l_{0}} \int_{0}^{t} \varepsilon_{r}(t) d t$

$$
\begin{aligned}
& \sigma(t)=\frac{A}{A_{0}} E \varepsilon_{t}(t) \\
& \sigma_{e}=\left(A+B\left(\varepsilon_{e}^{p}\right)^{n}\right)\left(1+C \ln \dot{\varepsilon}^{*}\right)\left(1-T^{* m}\right) \\
& T^{*}=\frac{T-T_{r}}{T_{m}-T_{r}} \\
& \sigma_{e}=A+B\left(\varepsilon_{e}^{p}\right)^{n} \\
& \ln \left(\sigma_{e}-A\right)=\ln B+n \ln \varepsilon_{e}^{p} \\
& \sigma_{e}=\left(A+B\left(\varepsilon_{e}^{p}\right)^{n}\right)\left(1+C \ln \dot{\varepsilon}^{*}\right) \\
& m=A^{*} \exp \left(-T / T_{1}\right)+m_{0}
\end{aligned}
$$

\section{References}

[1] J. Pamela, A. Bécoulet, D. Borba, J.L. Boutard, L. Horton, D. Maisonnier, Fusion Eng. Des. 84 (2009) 194-204.

[2] M. Rieth, J.L. Boutard, S.L. Dudarev, T. Ahlgren, S. Antusch, N. Baluc, M.F. Barthe, C.S. Becquart, L. Ciupinski, J.B. Correia, C. Domain, J. Fikar, E. Fortuna, C.C. Fu, E. Gaganidze, T.L. Galán, C. García-Rosales, B. Gludovatz, H. Greuner, K. Heinola, N. Holstein, N. Juslin, F. Koch, W. Krauss, K.J. Kurzydlowski, J. Linke, C. Linsmeier, N. Luzginova, H. Maier, M.S. Martínez, J.M. Missiaen, M. Muhammed, A. Muñoz, M. Muzyk, K. Nordlund, D. NguyenManh, P. Norajitra, J. Opschoor, G. Pintsuk, R. Pippan, G. Ritz, L. Romaner, D. Rupp, R. Schäublin, J. Schlosser, I. Uytdenhouwen, J.G. van der Laan, L. Veleva, L. Ventelon, S. Wahlberg, F. Willaime, S. Wurster, M.A. Yar, J. Nucl. Mater. 417 (2011) 463-467.

[3] H. Bolt, V. Barabash, G. Federici, J. Linke, A. Loarte, J. Roth, K. Sato, J. Nucl Mater. 307-311 (Part 1) (2002) 43-52.

[4] J. Roth, E. Tsitrone, A. Loarte, T. Loarer, G. Counsell, R. Neu, V. Philipps, S. Brezinsek, M. Lehnen, P. Coad, C. Grisolia, K. Schmid, K. Krieger, A. Kallenbach, B. Lipschultz, R. Doerner, R. Causey, V. Alimov, W. Shu, O. Ogorodnikova, A. Kirschner, G. Federici, A. Kukushkin, J. Nucl. Mater 390-391 (2009) 1-9.

[5] M. Rieth, S.L. Dudarev, S.M. Gonzalez de Vicente, J. Aktaa, T. Ahlgren, S. Antusch, D.E.J. Armstrong, M. Balden, N. Baluc, M.F. Barthe, W.W. Basuki, M. Battabyal, C.S. Becquart, D. Blagoeva, H. Boldyryeva, J. Brinkmann, M. Celino, L. Ciupinski, J.B. Correia, A. De Backer, C. Domain, E. Gaganidze, C. García-Rosales, J. Gibson, M.R. Gilbert, S. Giusepponi, B. Gludovatz, H. Greuner, K. Heinola, T. Höschen, A. Hoffmann, N. Holstein, F. Koch, W. Krauss, H. Li, S. Lindig, J. Linke, C. Linsmeier, P. López-Ruiz, H. Maier J. Matejicek, T.P. Mishra, M. Muhammed, A. Muñoz, M. Muzyk, K. Nordlund, D. Nguyen-Manh, J. Opschoor, N. Ordás, T. Palacios, G. Pintsuk, R. Pippan, J. Reiser, J. Riesch, S.G. Roberts, L. Romaner, M. Rosiński, M. Sanchez, W. Schulmeyer, H. Traxler, A. Ureña, J.G. van der Laan, L. Veleva, S. Wahlberg, M. Walter, T. Weber, T. Weitkamp, S. Wurster, M.A. Yar, J.H. You, A. Zivelonghi, J. Nucl. Mater. 432 (2013) 482-500.

[6] R.A. Pitts, S. Carpentier, F. Escourbiac, T. Hirai, V. Komarov, S. Lisgo, A.S. Kukushkin, A. Loarte, M. Merola, A. Sashala Naik, R. Mitteau, M. Sugihara, B. Bazylev, P.C. Stangeby, J. Nucl. Mater. 438 (2013) S48-S56.

[7] Y.T. Song, J.G. Li, Y.X. Wan, B.N. Wan, P. Fu, X. Gao, B.J. Xiao, Y.P. Zhao, C.D. Hu, G. Gao, IEEE Trans. Plasma Sci. 42 (2014) 415-420.

[8] G. Sannazzaro, P. Barabaschi, F. Elio, K. Ioki, N. Miki, M. Onozuka, Y. Utin, M. Verrecchia, H. Yoshimura, Fusion Eng. Des. 58-59 (2001) 863-867.

[9] S. Pak, H. Jhang, D.-K. Oh, D.Y. Ku, Fusion Eng. Des. 88 (2013) 3224-3237.

[10] H. Zhao, G. Gary, Int. J. Solids Struct. 33 (1996) 3363-3375.

[11] W.K. Rule, S.E. Jones, Int. J. Impact Eng. 21 (1998) 609-624.

[12] H. Kurishita, S. Matsuo, H. Arakawa, T. Sakamoto, S. Kobayashi, K. Nakai, T. Takida, M. Kato, M. Kawai, N. Yoshida, J. Nucl. Mater. 398 (2010) 87-92.

[13] Z. Pan, Y.Z. Guo, S.N. Mathaudhu, L.J. Kecskes, K.T. Hartwig, Q. Wei, J. Mater. Sci. 43 (2008) 7379-7384. 